\title{
Interventions to optimize medication use in nursing homes: a narrative review
}

\author{
Anne Spinewine ${ }^{1,2}$ (D) Perrine Evrard ${ }^{1} \cdot$ Carmel Hughes $^{3}$
}

Received: 20 October 2020 / Accepted: 25 February 2021 / Published online: 9 March 2021

(c) The Author(s) 2021

\section{Key summary points}

Aim This review aimed to identify, describe and discuss different interventions targeting medication use optimization in nursing homes and to identify research gaps.

Finding Prescription of the whole medication regimen or of specific medication classes was the most studied aspect. Medication review and multidisciplinary approaches appeared to be effective strategies in reducing appropriate use, but further large-scale randomized trials are needed.

Messages Efforts to optimize medication use among nursing home residents are still needed and should focus on less evaluated intervention components, specific medication classes and medication use aspects not related to prescribing.

\begin{abstract}
Purpose Polypharmacy, medication errors and adverse drug events are frequent among nursing home residents. Errors can occur at any step of the medication use process. We aimed to review interventions aiming at optimization of any step of medication use in nursing homes.

Methods We narratively reviewed quantitative as well as qualitative studies, observational and experimental studies that described interventions, their effects as well as barriers and enablers to implementation. We prioritized recent studies with relevant findings for the European setting.

Results Many interventions led to improvements in medication use. However, because of outcome heterogeneity, comparison between interventions was difficult. Prescribing was the most studied aspect of medication use. At the micro-level, medication review, multidisciplinary work, and more recently, patient-centered care components dominated. At the macrolevel, guidelines and legislation, mainly for specific medication classes (e.g., antipsychotics) were employed. Utilization of technology also helped improve medication administration. Several barriers and enablers were reported, at individual, organizational, and system levels.

Conclusion Overall, existing interventions are effective in optimizing medication use. However there is a need for further European well-designed and large-scale evaluations of under-researched intervention components (e.g., health information technology, patient-centered approaches), specific medication classes (e.g., antithrombotic agents), and interventions targeting medication use aspects other than prescribing (e.g., monitoring). Further development and uptake of core outcome sets is required. Finally, qualitative studies on barriers and enablers for intervention implementation would enable theory-driven intervention design.
\end{abstract}

Anne Spinewine

anne.spinewine@uclouvain.be

1 Clinical Pharmacy Research Group, Louvain Drug Research

Institute, Université Catholique de Louvain, Avenue Mounier

72/B1.72.02, Woluwe-Saint-Lambert, 1200 Brussels,

Belgium

2 Pharmacy Department, CHU UCL Namur, Université

Catholique de Louvain, Yvoir, Belgium

3 School of Pharmacy, Queen's University Belfast, Belfast, UK 
Keywords Nursing homes $\cdot$ Older adults $\cdot$ Medication optimization $\cdot$ Potentially inappropriate prescriptions $\cdot$ Interventions . Implementation

\section{Introduction}

Medication use among nursing home residents (NHRs) is very common. Indeed, in nursing homes (NHs), polypharmacy is highly prevalent, with $91 \%, 74 \%$ and $65 \%$ of NHRs taking more than five, nine and 10 medications, respectively [1]. These rates of polypharmacy are higher than what has been reported in home-dwelling older adults (27.0-59.0\% taking 5 or more medications [1]). Factors associated with polypharmacy among NHRs include age, cognitive status, number of prescribers, dependency and length of stay in the NH [1].

Polypharmacy, together with other factors such as altered pharmacokinetics and pharmacodynamics, and complexity of the medication use process, makes the safe use of medications for NHRs highly challenging [2]. Reported rates of adverse drug events (ADEs) in NHs range from 1.89 to 10.8 per 100 resident-months [3]. Medication errors (MEs) are common, involving 16-27\% of NHRs in studies evaluating all types of MEs and 13-31\% of NHRs in studies evaluating MEs occurring at transfer from and to other settings of care [4]. MEs can occur at any step of the medication use process. These steps include: prescribing, purchase and ordering, delivery, storage, preparation and administration, monitoring and medication reconciliation at transfer [5]. The minimum practices that are required to deliver high-quality care at each step have been identified and constitute opportunities for evaluation of performance [5]. The literature suggests that the majority of errors occur at the prescribing, monitoring, administration, and medication reconciliation steps [4]. In a recent review, five categories of factors related to the work system were found to affect medication safety in NHs: persons (resident and staff, e.g., number of medications, staff medication knowledge), organization (e.g., inter-professional collaboration, staff/resident ratio), tools and technology (e.g., bar-code medication system), tasks (e.g., workload and time pressure), and environment (e.g., staff interruption) [3]. It is expected that interventions to optimize medication use in $\mathrm{NHs}$ would address these steps and factors as priorities.

The prescribing component is an important aspect of medication optimization, as prevalence of potentially inappropriate prescriptions (PIPs) is high, and as PIP and polypharmacy have been associated with adverse outcomes such as lower quality of life, hospitalizations, falls, and frailty [1, 6-8]. PIPs encompass underprescribing (failure to prescribe a needed drug), overprescribing (prescribing more drugs than needed) and misprescribing (incorrect prescribing of a needed drug) [2]. The estimated prevalence of PIPs among NHRs is $43.2 \%$ [9]. This prevalence tends to rise over time and the situation is more concerning in Europe, with higher reported point prevalence (49.0\%) than these reported in North America (26.8\%) or other countries (29.8\%) [9]. Several factors were found to be associated with PIPs such as total number of medications taken, age, location of the $\mathrm{NH}$ (including country, urban versus rural), dementia and comorbidity burden $[9,10]$. The most commonly reported inappropriate medications include psychotropic drugs, medications with anticholinergic properties, antimicrobials, nonsteroidal anti-inflammatory drugs and proton-pump inhibitors $[9,11,12]$.

Interventions to optimize medication use can be implemented at different levels of the health care system. Throughout the literature there is inconsistency in the number and definitions of these levels [13]. For this review, we distinguish between two levels. First, the micro-level refers to interventions implemented at the $\mathrm{NH}$ level and directed at NHRs, health care providers (HCPs) and organization of the NH itself. Second, the macro-level (also called systemlevel) encompasses strategies that are external to NHs but impact on their practice. These are typically but not exclusively defined at a national or regional level.

The main objective of this review is to identify, describe and discuss interventions aimed at optimization of any step of medication use in $\mathrm{NH}$, in terms of content, effects, as well as barriers and enablers to their implementation. As a second objective, we aimed to identify perspectives for the future at the research and practice levels.

\section{Method}

This review was conducted using a narrative process. We focused on interventions targeting the medication use of residents living in NHs. Relevant references were identified and selected from a search in PubMed, the authors' existing knowledge of literature, and recent publications in geriatrics journals. Finally, we retrieved additional studies by handsearching reference lists of identified articles. Searching additional databases (e.g., Embase, CINAHL) would have been valuable and relevant in the context of a systematic review, but this was beyond the scope of the present work.

We selected quantitative as well as qualitative studies, observational and experimental studies that described interventions, their effect as well as barriers and enablers. We only included peer-reviewed research published in English. Given the large volume of literature, we prioritized results from the most recent (systematic) reviews and original 
studies published after these reviews were completed. We did not restrict the country where research took place, but gave preference to studies conducted in Europe or with relevant data or messages for European settings, as judged by the research team. We did not include papers focusing on medication optimization at end of life or during palliative care which was considered beyond the scope of this review. The search strategy and papers' selection process are presented in Fig. 1.

Because an important part of the literature focuses on the prescribing component, we first review this aspect, followed by approaches to improve other aspects of medication use. In the section on prescribing, we review separately the approaches concerned with optimizing the whole medication regimen and those concentrating on specific drugs or classes, because the approaches, their effect, as well as barriers and enablers may differ, and hence, merit separate consideration.

\section{Interventions to optimize prescribing for the whole medication regimen}

Three recent systematic reviews (SRs) evaluated the effect of micro-level interventions-largely based on medication review (MR) - to optimize prescribing in the $\mathrm{NH}$ setting and reported positive results on quality of prescribing [14-16]. A Cochrane SR highlighted four different approaches for optimization: MR, multidisciplinary case-conferencing, education for HCPs, and use of clinical decision support system (CDSS) [14]. These were used either alone, or in combination. Overall, the interventions led to identification and resolution of drug-related problems, but there was no consistent effect on resident-related outcomes [14]. In a second SR focusing on MR and including experimental and observational study designs, interventions were associated with a reduction in prescribed medications, inappropriate medications and adverse outcomes (including deaths and hospitalizations) [15]. However, high-quality clusterrandomized controlled trials evaluating CDSS effects or evaluating the impact of multidisciplinary interventions on well-defined important resident-related outcomes were lacking $[14,15]$. In terms of deprescribing, a SR of specific interventions reported a reduction of 59\% of NHRs receiving at least one PIP [16]. Only interventions including a MR were associated with a reduction in all-cause mortality and number of fallers [16].

Five trials performed in European Union (EU) countries NHs were published after these SRs and are summarized in Table $1[11,17-20]$. These were all multicenter studies-three were cluster-randomized controlled trials-and involved multidisciplinary interventions mainly consisting of education of HCPs and MR. None involved a CDSS component. Participation of NHR was one component of the intervention in two studies. The study by Wouters et al. involved NHRs through a questionnaire on their preferences and experiences as a step of MR [18]. In the COSMOS study, NHRs were asked about their interest in participating in different activities [20]. Overall, results from these five trials were consistent with those of
Fig. 1 Search strategy and papers' selection process

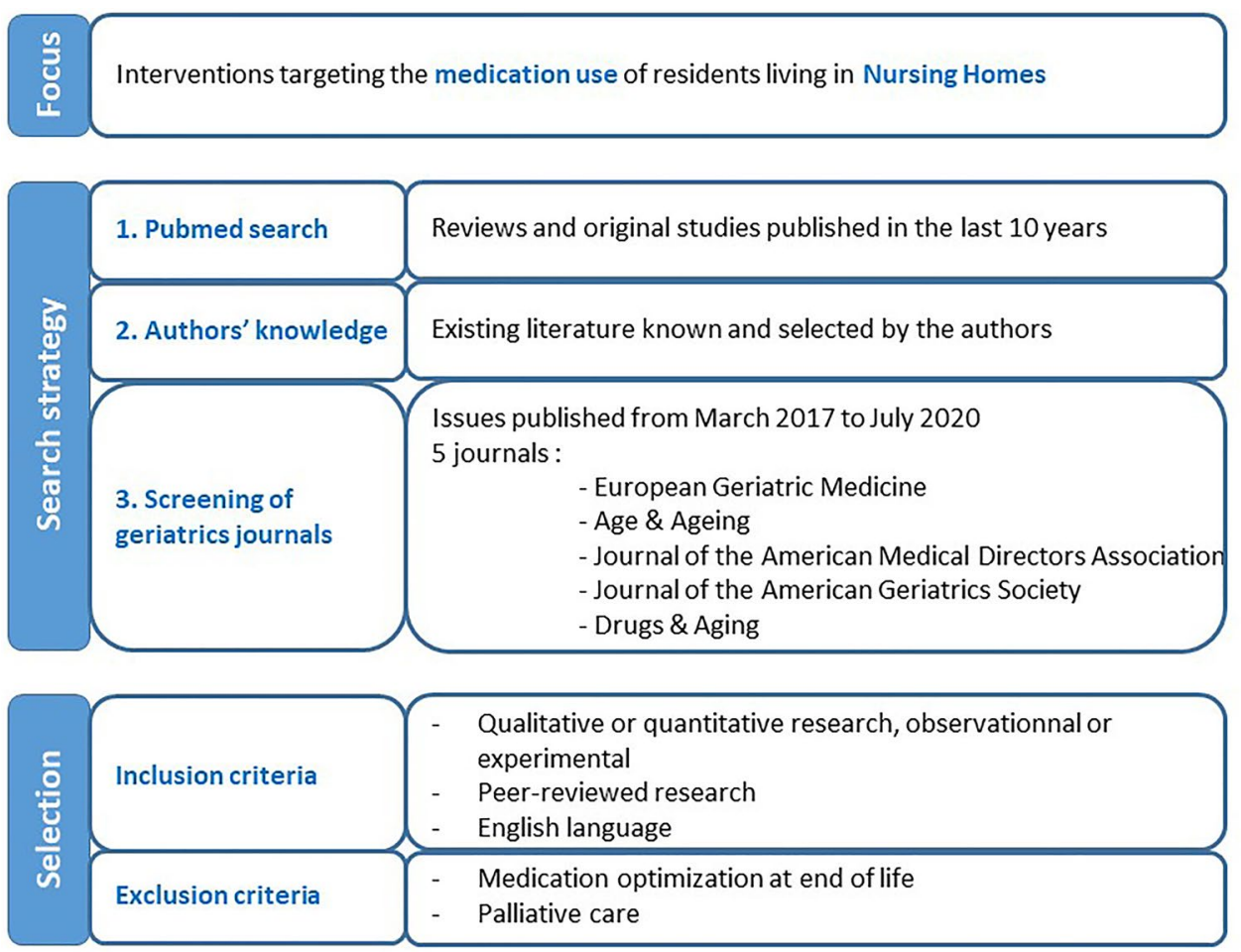




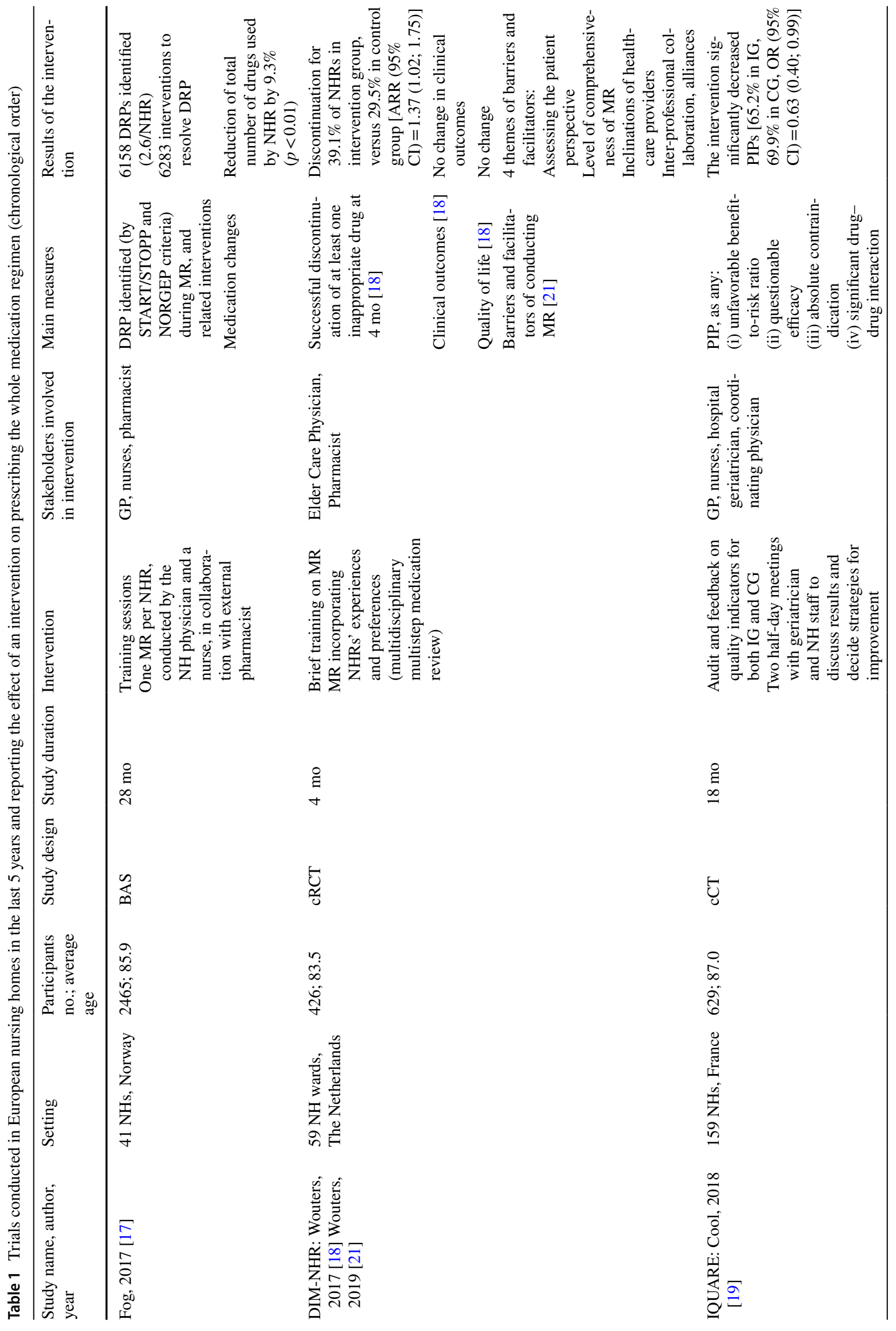




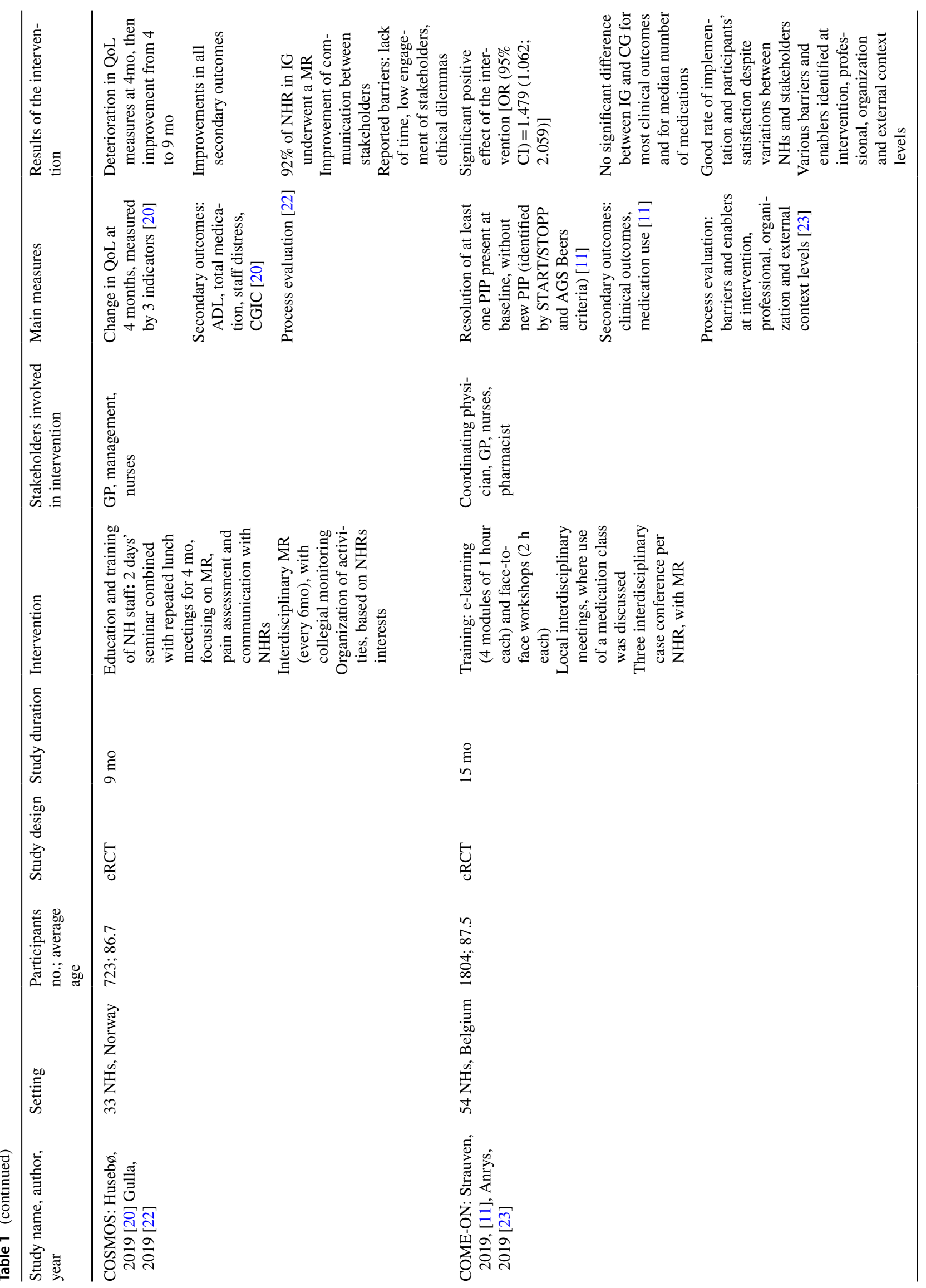


previous SRs, with positive effects on polypharmacy and PIPs-although the measures used to define PIPs varied widely across studies, and none of the tools used were specific to the NH setting. Clinical and humanistic outcomes were inconsistently evaluated (Table 2). Two trials reported no effect of the intervention on clinical outcomes and/or quality of life $[11,18]$. In the COSMOS study, an initial decline in quality-of-life was found in the intervention group-initial NHR unhappiness with the MR is one of the possible explanations raised by the authors-but this decrease reversed significantly during follow-up [20].

Beyond the evaluation of the effect of interventions, a clear understanding of the enablers and barriers to implementation and success is crucial for the development of future interventions. It is encouraging to see that three of the trials presented in Table 1 addressed this question, mainly through questionnaires and interviews of HCPs [21-23]. Wouters et al. also interviewed NHRs [21]. Overall, the interdisciplinary approaches were recognized as key elements for the success of interventions, despite organizational and time constraints. The attitude, role and competency of HCPs (physicians, pharmacists and nurses) were identified both as barriers and enablers. The need for funding MRs at the macro-level was also reported. Assessing the patient perspective was reported to be a delicate balance between the value and the barriers to a proper assessment of the patient perspective. Other qualitative studies assessed the specific barriers and enablers of deprescribing in the $\mathrm{NH}$ setting $[24,25]$. While many were similar to what was reported for intervention implementation, HCPs' concerns about deprescribing and perceived reluctance of NHRs to change were more specific to deprescribing interventions. This highlights the need for deprescribing guidance and shared decision-making [24, 25].

\section{Interventions to optimize prescribing for specific drug classes}

In the section below, we focus on three medication classes for which inappropriate use is highly prevalent and is a threat to patient safety. For each of these, we first briefly describe data on their (inappropriate) use, then review the evidence on approaches for optimization, as well as barriers and enablers for improvement. Table 3 describes five recent studies conducted in NHs in Europe, four on psychotropic drugs and one on anti-infective drugs. We found no recent EU study focusing on DAP.

\section{Psychotropic drugs}

Psychotropic drugs are used extensively in $\mathrm{NHs}$, with wide variation in rates of prescribing between countries. In NHs in 
Table 2 Outcomes and process measures reported in trials conducted in European nursing homes in the last 5 years

\begin{tabular}{|c|c|c|c|c|c|c|c|c|}
\hline \multirow[t]{2}{*}{ Study } & \multicolumn{2}{|c|}{ Intermediate outcomes } & \multicolumn{3}{|l|}{ Clinical outcomes } & \multirow{2}{*}{$\begin{array}{l}\text { Humanistic } \\
\text { outcome } \\
\text { Quality of life }\end{array}$} & \multicolumn{2}{|c|}{ Process measures } \\
\hline & $\begin{array}{l}\text { Medication use } \\
\text { (general medica- } \\
\text { tion or specific) }\end{array}$ & PIP & Healthcare use & Mortality & Others & & $\begin{array}{l}\text { Imple- } \\
\text { mentation } \\
\text { rate }\end{array}$ & $\begin{array}{l}\text { Barri- } \\
\text { ers and } \\
\text { enablers }\end{array}$ \\
\hline Fog, 2017 [17] & $\begin{array}{l}\text { Number of } \\
\text { medications, } \\
\text { Medication } \\
\text { change }\end{array}$ & $\begin{array}{l}\text { Categories of } \\
\text { drug-related } \\
\text { problems }\end{array}$ & & & & & & \\
\hline $\begin{array}{l}\text { DIM-NHR: } \\
\text { Wouters, } 2017 \\
\text { [18] Wouters, } \\
2019 \text { [21] }\end{array}$ & & $\begin{array}{l}\text { DBI } \\
\text { PIP discontinu- } \\
\text { ation }\end{array}$ & $\begin{array}{l}\text { Visit to outpa- } \\
\text { tient clinic } \\
\text { Visits by HCPs }\end{array}$ & & $\begin{array}{l}\text { Falls } \\
\text { Cognitive func- } \\
\text { tion } \\
\text { (SIB-S, MMSE) }\end{array}$ & $\begin{array}{l}\text { EQ-5D-3L } \\
\text { DQI }\end{array}$ & $\mathrm{X}$ & $X$ \\
\hline $\begin{array}{l}\text { IQUARE: Cool, } \\
2018 \text { [19] }\end{array}$ & & $\begin{array}{l}\text { PIP as defined } \\
\text { by the authors }\end{array}$ & & & & & & \\
\hline $\begin{array}{l}\text { COSMOS: } \\
\text { Huseb } \varnothing, 2019 \\
\text { [20] Gulla, } \\
2019 \text { [22] }\end{array}$ & $\begin{array}{l}\text { Number of } \\
\text { medications } \\
\text { Use of specific } \\
\text { medication } \\
\text { classes }\end{array}$ & & & & $\begin{array}{l}\text { CGIC } \\
\text { Neuropsychiat- } \\
\text { ric symptoms } \\
\text { ADL }\end{array}$ & $\begin{array}{l}\text { QUALIDEM } \\
\text { QUALID } \\
\text { EQ-VAS }\end{array}$ & $\mathrm{X}$ & $X$ \\
\hline $\begin{array}{l}\text { COME-ON: } \\
\text { Strauven, } \\
2019, \\
\text { [11], Anrys, } \\
2019 \text { [23] }\end{array}$ & $\begin{array}{l}\text { Number of } \\
\text { medications } \\
\text { Use of specific } \\
\text { medication } \\
\text { classes }\end{array}$ & $\begin{array}{l}\text { START/STOPP } \\
\text { criteria } \\
\text { AGS Beers } \\
\text { criteria }\end{array}$ & $\begin{array}{l}\text { Hospital admis- } \\
\text { sions } \\
\text { Visits to ED } \\
\text { Visits to GO } \\
\text { or specialist } \\
\text { physicians }\end{array}$ & $\mathrm{X}$ & & & $\mathrm{X}$ & $\mathrm{X}$ \\
\hline $\begin{array}{l}\text { PROPER II, Van } \\
\text { der Spek, } 2018 \\
{[26]}\end{array}$ & & APID index & & & & & & \\
\hline $\begin{array}{l}\text { EPCentCare, } \\
\text { Richter, } 2019 \\
\text { [27] }\end{array}$ & $\begin{array}{l}\text { Antipsychotic } \\
\text { users }\end{array}$ & & Fall-related & & $\begin{array}{l}\text { Falls } \\
\text { Agitated behav- } \\
\text { ior } \\
\text { Restraint use }\end{array}$ & QoL-AD & $\mathrm{X}$ & $\mathrm{X}$ \\
\hline $\begin{array}{l}\text { Weeks, } 2018 \\
\text { [28] }\end{array}$ & $\begin{array}{l}\text { Change in } \\
\text { psychotropics } \\
\text { dose } \\
\text { Medication dis- } \\
\text { continuation }\end{array}$ & & & $X$ & $\begin{array}{l}\text { Falls } \\
\text { Restraint use }\end{array}$ & & & \\
\hline $\begin{array}{l}\text { Wauters, } 2019 \\
\text { [29] }\end{array}$ & $\begin{array}{l}\text { Long-term psy- } \\
\text { chotropics } \\
\text { Concomitant } \\
\text { psychotropics }\end{array}$ & & & & & & & \\
\hline $\begin{array}{c}\text { Plüss-Suard, } \\
2020[30]\end{array}$ & Antibacterial use & & & & & & & \\
\hline
\end{tabular}

$A D L$ activities of daily living, AGS American Geriatrics Society, APID appropriate psychotropic drug use in dementia index, $C G I C$ Clinical Global Impression of Change, DBI Drug Burden Index, $D Q I$ dementia quality of life instrument, $E D$ emergency department, $E Q-5 D-3 L$ EQVAS European quality of life visual analog scale, $H C P$ s health care providers, $Q o L-A D$ quality of life in Alzheimer's disease scale, $Q U A L I D$ quality of life late-stage dementia scale, $Q U A L I D E M$ quality of life dementia scale, MMSE mini-mental state examination, $P I P$ potentially inappropriate prescription, $S I B-S$ severe impairment battery-short, START/STOPP screening tool to alert doctors to right treatment/screening tool of older persons' prescriptions. ' $\mathrm{X}$ ' without further detail means that the outcome was reported, but no details on measurement were given.

Western European countries, antipsychotic use ranges from 12 to $59 \%$ of NHRs and antidepressant use is even higher, from 19 to $68 \%$ [31]. The use of benzodiazepine receptor agonists (BZRA, namely benzodiazepines and Z-drugs) ranges from $14.6 \%$ (Canada, [32]) to $54.4 \%$ (France, [33]).
Concomitant use of several psychotropic drugs is also high with $31.5 \%$ of NHRs taking two or more such medications [29].

Beyond this high prevalence of use, frequent inappropriate use is a concern. Indeed, psychotropic drugs are often the 


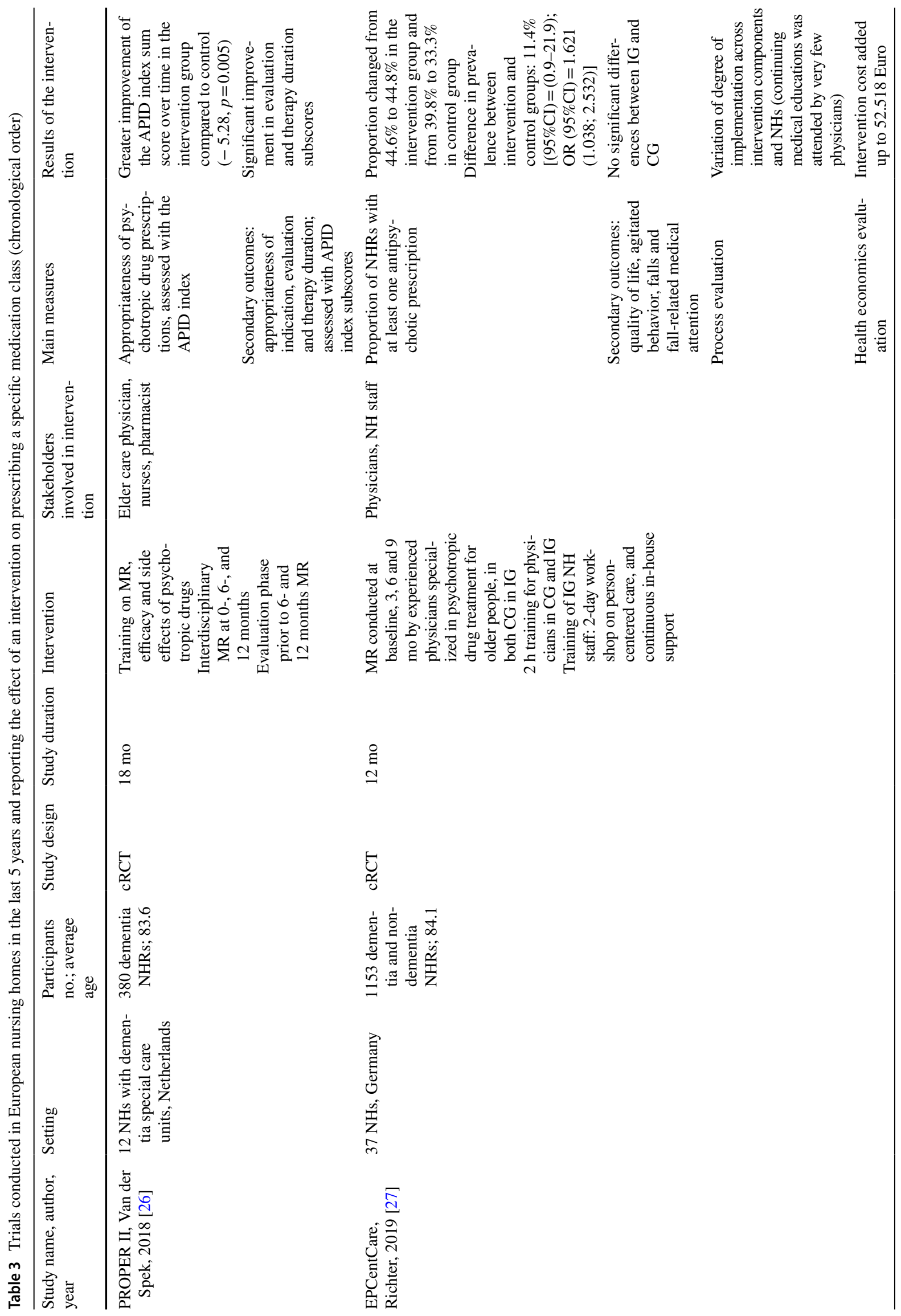




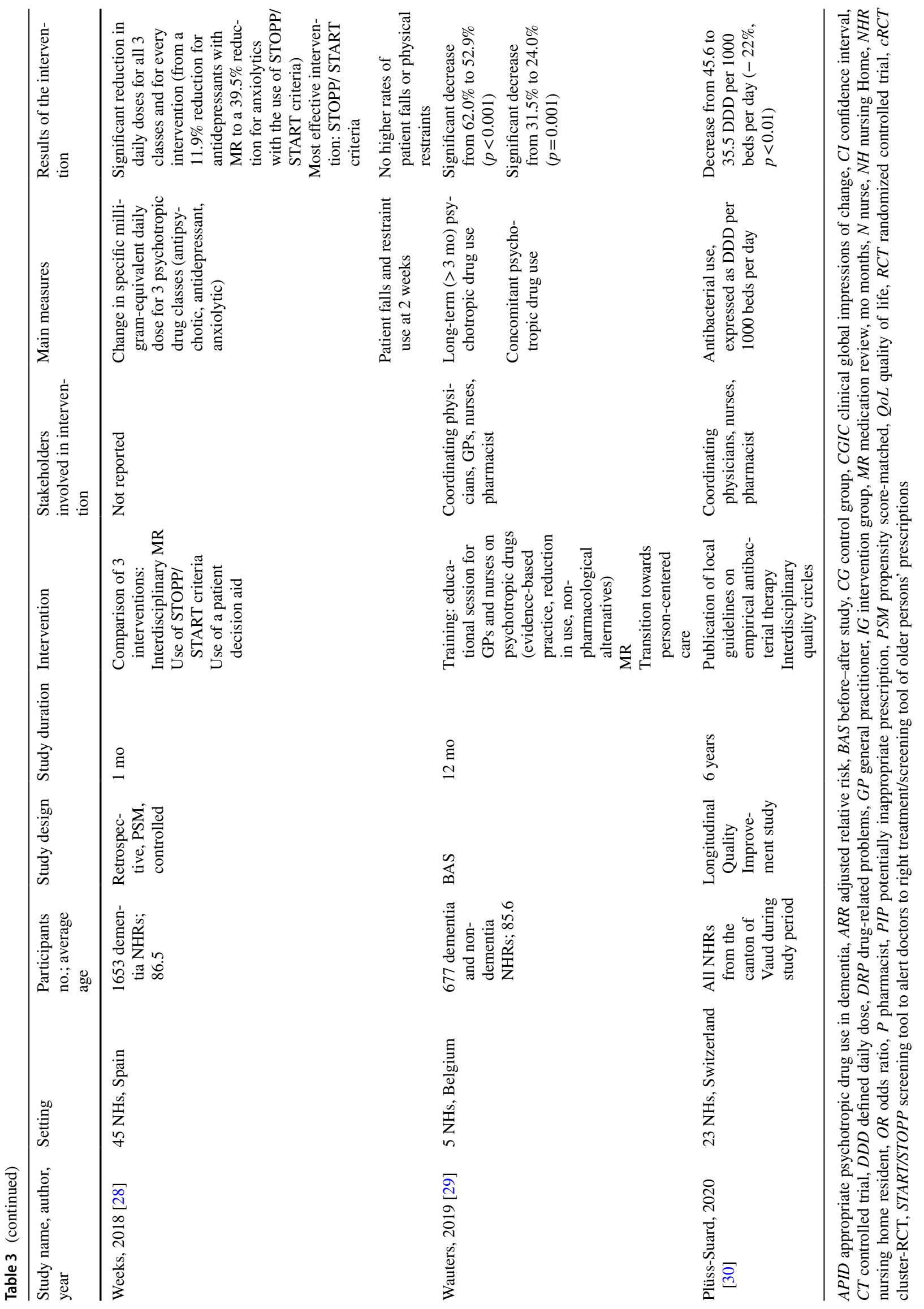


most commonly reported inappropriate medications among NHRs [9, 11, 34]. The inappropriate (and off-label) use of antipsychotics for behavioral and psychological symptoms of dementia has received the most attention. This has led to national and international calls and programs for deprescribing of antipsychotics in NHs. Even though the appropriateness of antidepressants and BZRA use has been less widely studied, recent data suggest that these medicines should also give rise to concern. In a study with 2651 French NHRs receiving an antidepressant, PIP (with regard to indication, drug class, duplication and monitoring) was found in $38.4 \%$ of NHRs [35]. In a Belgian study with 418 NHRs taking a BZRA, 98\% of NHRs received the BZRA for more than 4 weeks, and drug-disease and drug-drug interactions were found in two-thirds of users overall [36]. In both studies, dementia was associated with less PIP.

Data on the factors associated with (inappropriate) psychotropic drug use suggest that approaches for improvement can be considered both at the macro- and micro-levels. A recent SR found that organizational capacity, individual professional capacity, attitudes, communication and collaboration and regulation or guidelines influenced antipsychotic prescribing [37]. Similarly, factors associated with psychotropic drugs use included: staffing level or education, teamwork and communication between both on-site and visiting staff, and managerial expectations [13].

At the macro-level, a recent scoping review including 36 studies (of which only three were performed in Europe) found that mandatory strategies such as legislation (e.g., change in reimbursement, initiation of public reporting of antipsychotic use) had greater evidence of impact on drug utilization than non-mandatory macro-level strategies such as guidelines and recommendations [13]. The OBRA-87 legislation in the US led to the greatest reduction in psychotropic drug use. However, inappropriate use remains a significant issue and few studies have examined both sustainability of system-level strategies and cost-related outcomes [13].

At the micro-level, a recent narrative review of approaches for deprescribing psychotropic medications in NHRs with dementia reported that interventions should have more than one component, include multidisciplinary teams and HCPs' training, and be person-centered [38]. The same intervention components were highlighted in a SR of factors influencing antipsychotic use among dementia NHRs [37] and in a review of interventions targeting BZRA deprescribing [39]. In Europe, a few interventions were recently evaluated, with encouraging results (Table 3 [26-29]). Similar to approaches targeting the whole medication regimen, training of HCPs and MR were important components of evaluated strategies. However, some more specific strategies were also tested. Patient-centered interventions were implemented in three studies. In Belgium, a quality improvement study with transition to person-centered care (e.g., through the implementation of meaningful activities for NHRs) showed a reduction in both long-term use and concomitant use of psychotropics [29]. In a Spanish study with NHRs with dementia, application of STOPP/START criteria and use of decision aids for NHRs had positive and similar effects on reducing daily dosages of psychotropic drugs, even though decision aids were less often used than STOPP/START [28]. Richter et al. investigated a person-centered care approach, which had been successfully evaluated in NHs in the UK, and adapted it to the German context. However, the program did not lead to a reduction in antipsychotic prescriptions. Reasons for differences between the UK and Germany were unclear, but the culture of care as reflected in the attitudes and beliefs of nursing staff and a lack of cooperation with physicians may have accounted for the findings [27].

\section{Drugs with anticholinergic properties (DAP)}

DAPs are associated with a wide range of peripheral and central adverse effects (e.g., delirium, fall, urinary retention), and there have been numerous calls to reduce their use [40]. A recent population-based study among NHRs with depression even found that clinically significant anticholinergic use was associated with a $31 \%$ increase in risk of death [41]. Despite such concerns, DAP are highly prevalent among NHRs. In a study conducted in Helsinki, in 2011, $85 \%$ of NHRs were taking at least one DAP [42]. Positive findings were reported in a study evaluating temporal trends from 2003 to 2017 (the anticholinergic burden decreased, and participants with dementia had a lower anticholinergic burden), but DAP use - especially antipsychotics and antidepressants-remained high [43]. This calls for action toward DAP use in NH.

A SR reported that (micro-level) interventions aiming at reducing anticholinergic burden in older adults $(\geq 65)$ in different settings often reduced anticholinergic burden [40]. Pharmacists delivered the intervention in the majority of studies, and authors concluded that these HCPs may be well placed to implement a DAP reduction intervention [40]. Among the eight studies included, only one was conducted in NHs, in Norway. The intervention consisted of a pharmacist-initiated reduction of anticholinergic drug scale score after multidisciplinary MR. Anticholinergic drug scale scores were significantly reduced in the intervention group and remained unchanged in the control group. However, no improvement in NHRs' cognitive function at 8 weeks was observed [44]. In another recent study conducted in New Zealand NHs, pharmacists performed deprescribing recommendations for both anticholinergic and sedative drugs. This showed that deprescribing was feasible, with $72 \%$ of recommendations implemented by physicians, without deterioration in quality of life, and with an improvement in depression 
and frailty scores [45]. No macro-level approaches specifically targeting DAP use were found.

These data are encouraging but remain very limited, which calls for further well-conducted, large-scale, controlled studies. The variety and heterogeneity of tools to measure and quantify anticholinergic burden remains an issue, as there is no consensus as to which of the tools is most useful in research or clinical settings [42].

\section{Anti-infective drugs}

Antimicrobials are commonly prescribed in NHs and their use is associated with antimicrobial resistance and Clostridium difficile infections. The 2016-2017 point prevalence survey performed in NHs in $24 \mathrm{EU}$ countries found a crude prevalence of NHRs receiving at least one antimicrobial agent of $4.9 \%$, with large variations across and between countries (from $0.7 \%$ in Lithuania to $10.5 \%$ in Spain and Denmark) [46]. Prophylaxis for urinary-tract infection was a frequent—and potentially inappropriate [47]—indication for antimicrobial use (representing almost one third of prescriptions) and did not significantly decline following previous surveys [46]. Inappropriate prophylactic use of antimicrobials was therefore recommended as a specific target for future interventions. Appropriate prescribing of antimicrobials in $\mathrm{NH}$ is challenging and influenced by several factors, such as variations in knowledge and practice among HCPs, social factors, antimicrobial resistance and the specific context of $\mathrm{NH}$ care (including restricted access to doctors and diagnostic tests) [12].

Antibiotic stewardship programs (ASPs) are coordinated interventions promoting the appropriate use of antibiotics to improve patients' outcomes and reduce microbial resistance [48], which can be implemented at both the macro- and micro-levels. At the macro-level, ASPs have been mandated in American NHs since November 2017. In Europe, data on ASP indicate that there has been no increase in ASP implementation over time, and improvements in antimicrobial stewardship are urgently needed in EU NHs [46].

Recent SRs on ASP in the NH setting reported that the most commonly implemented strategies were educational materials, educational meetings, and guideline implementation, combined in multifaceted interventions [49]. Results suggested an effect on intermediate health outcomes, such as antibiotic consumption or adherence to antibiotic guidelines. However, an effect on key health outcomes such as mortality rates, hospitalizations, or Clostridium difficile infection rates was not demonstrated [48-50]. Moreover, the specific benefit of intervention components is unclear. In Switzerland, ASP activities including local multidisciplinary networks (micro-level strategy) and guidelines publication (macro-level strategy) led to a $22 \%$ reduction in antibacterial use over a 6-year period (Table 2) [30]. A recent paper described the ASP implementation experience in four European countries (Norway, The Netherlands, Poland and Sweden) where various regional or national ASP initiatives have recently been introduced [51]. The ASP components included national surveillance systems, $\mathrm{NH}$-specific prescribing guidelines and national networks of healthcare institutions. No data were provided to document the effect of these initiatives on antimicrobials consumption. Future ASP implementation will need to account of enablers (e.g., the presence of study leaders, skills training for doctors and nurses, and good inter-professional communication) and barriers (e.g., pressures from residents and families, $\mathrm{NH}$ staff's knowledge and belief) in order to be successful, in addition to outcome data [12, 52].

\section{Interventions to optimize medication reconciliation at transfer}

The transition of NHRs from one setting to another increases the risk for MEs. Indeed, preventable ADEs at transition points account for $46-56 \%$ of all MEs [53] and MEs have been identified as a major source of morbidity and mortality in transitional care [54]. A possible explanation is poor communication between settings, potentially leading to prescribing errors. When questioned on ways to improve quality and safety of care transfer, $\mathrm{NH}$ and emergency department staff raised several strategies, including the use of a standardized transfer form, a checklist and verbal communication between settings [55].

In practice, some of these interventions have been studied at micro-level. Results from a SR on interventions to improve transitional care between $\mathrm{NH}$ and hospitals show that the development of a standardized unique transfer document may assist with the communication of medication lists, and that pharmacist-led review of medication lists may help identify omitted or indicated medications on transfer [54]. This is supported by results from another SR evaluating medication reconciliation interventions during NHRs' transfer from and to the NH [53]. In most studies, a clinical pharmacist performing MR was part of the intervention. All interventions led to outcome improvement, but no study showed strong evidence in reducing medication discrepancies [53].

Existing data also suggest that HCPs believe that initiatives should be taken at the macro-level, to standardize processes during transitions. National guidance and toolkits relative to medication reconciliation in the $\mathrm{NH}$ setting exist in some countries such as Canada [56], but to the best of our knowledge, the impact of these initiatives on quality and safety of medication use in NHs has not been evaluated. 


\section{Interventions to optimize the preparation and administration}

The preparation and administration of prescribed drugs often falls to nurses (and sometimes pharmacists for the preparation stage) - and not to NHRs themselves. Medication administration errors (MAEs) encompass different types of errors such as wrong-time errors, wrong-dose errors, omitted doses, wrong-patient errors. As an example, $27 \%$ of calls to the Quebec Poison Center for patients aged over 65 resulted from drug administration to the wrong NHR [57]. The medication administration process is prone to interruptions, and this may increase the risk of MAE. It has been reported that nurses are interrupted at a rate ranging from 0.4 to 14 times an hour [58]. Swallowing difficulties may also trigger MAEs. Indeed, it is common for nurses to modify medication dosage forms through crushing tablets or opening capsules, in order to administer a medication to NHRs with swallowing difficulties [59]. Nurses reported that this practice is challenging and would need appropriate guidelines and training [59].

To reduce the risk of MAEs and resulting harms, different approaches have been taken, and the main focus has been the implementation of technological solutions, such as electronic medication administration record (eMAR) and bar-code medication administration [58, 60-62]. These technologies might be time-saving, decrease the probability of MAEs such as omitted doses and increase nurse satisfaction [61, 62]. However, a SR on eMAR in long-term care facilities reported that eMAR implementation is low, partly because of cost barriers, and there is a lack of rigorously designed research to inform administrators and clinicians about the effect of eMARs and bar-code medication administration on MEs [60]. The use of multi-compartment compliance aids is another possible approach to reduce preparation and administration errors. A recent study in London reported that MAE rate was higher with original medication packaging than with multi-compartment compliance aids (risk ratio $=3.9,95 \%$ CI 2.4-6.1) [63]. Limitations to their use included reduced staff alertness during administration and difficulties in identifying medication [63].

\section{Discussion}

This review has highlighted that many interventions focusing on the key steps in medicine optimization led to improvement in medication use. However, some components have not been comprehensively evaluated or not in powerful designs such as randomized controlled trials. In much of the literature reviewed, there was an under-representation of aspects of medication use not related to prescribing (including monitoring). This is perhaps not surprising due to the predominance of the prescribing process in healthcare, but other aspects of medication use do require further consideration. Many studies that did focus on prescribing had common intervention components. At the micro-level MR, multidisciplinary work, and more recently, patient-centered care components dominated; at the macro-, guidelines and legislation, mainly for specific medication classes, e.g., antipsychotics, were employed. Improving administration was achieved through utilization of technology.

What was also apparent in the studies examined was the marked heterogeneity in outcome reporting and measurement across studies (Table 2). This makes synthesis of findings difficult and highlights the need for a more common approach across studies examining similar research questions. This may be realized through the development and use of core outcome sets (COSs). Two relevant COSs exist, for trials aimed at optimizing prescribing among NHR [64] and for trials of MR in multi-morbid older patients with polypharmacy [65]. Several outcomes of these COSs have been under-evaluated (i.e., what to measure), such as pain relief, all-cause mortality, falls, quality of life, hospital admissions and emergency visits to hospital. These are clearly important outcomes for this particular population and for the health systems. It is important that future trials refer to and use a COS. Furthermore, approaches to measurement of outcomes (i.e., how to measure) were also highly variable. PIP was measured in most studies, but a wide range of tools was used. Although many were targeted at older adults, such tools may not be appropriate for NHRs who have a higher degree of frailty. The use of tools that have been specifically developed for those who are frail [47] or living in residential care (stoppNH [66]) may be a better option.

System level (macro-level) approaches were implemented in US and Australia, but much less so in Europe. Positive effects were seen with mandatory/legislative initiatives, and it could be argued that these should be considered at the European level. However, there has been a tradition of different countries tackling approaches in nursing home care in different ways which may be a function of different cultural and political contexts [67]. Many of the concerns around prescribing of key medicines such as antipsychotics and antiinfectives are universal, and a more comprehensive, crosscountry approach may be warranted.

At the micro-level, the importance of patient-centered interventions was increasingly recognized. Patient involvement or participation in the interventions was identified in two recent EU studies focusing on psychotropic drugs [28, 29], and in one of the studies to improve prescribing for the whole medication regimen [18]. However, more research on how best to involve NHRs, and NHRs with dementia in particular, is required. In some countries, patient and public involvement is increasingly expected as part of applications for research funding [68]. A recent study introduced 
weekly participatory action research sessions. During these, NHRs could discuss NH initiatives and suggest improvement. Results reported a positive NHR experience and an improved quality of life [69]. However, this is a challenging area as many NHRs will have varying levels of cognitive impairment, which may limit the level of their participation.

This paper focused on a number of specific medication classes which, historically, have been viewed as problematic in this population. With regard to psychotropics, a particular focus has been on reducing the use of antipsychotic drugs, but there was little exploration of any compensatory increases in the use of other sedating psychotropic drugs [70] or in the use of non-pharmacological approaches. Measurement of clinical and humanistic outcomes was limited and heterogeneous [27], therefore, a COS for interventions targeting psychotropic/antipsychotic drug use in $\mathrm{NHs}$ would be welcome. Indeed, this was also seen with studies focusing on DAPs, with a plethora of scales available, but little overlap to facilitate comparison. Anti-infectives have also been extensively studied in the $\mathrm{NH}$ environment. There has been no concerted attempt to introduce macro-level interventions focusing on ASP, which may reflect differing prescribing practices and cultures [71], but there have been efforts to begin to standardize the important outcomes for ASP interventions [72].

We selected the medication classes above because of a legacy of concern over inappropriate use. However, other medication classes also deserve specific focus, but have been ignored. Pain control is one of the outcomes of a COS of MR in older people [65]. Inappropriate prescribing of analgesics, and opioids in particular has been described in NHRs [73-75]. Second, there has been little work focusing on optimizing the use of antithrombotic agents among NHRs. This is an important research gap, as bleeding and thrombotic events are the most frequent ADEs [4]. Third, data on the deprescribing of medications used for cardiovascular prevention (e.g., statins, aspirin) and for diabetes would also be welcome, as no or very limited data are available [76-78]. Finally, the use of proton-pump inhibitors (PPIs) is highly prevalent and often inappropriate [79, 80]. While factors associated with both PPIs use and discontinuation have been described [79, 81], we found only one single-center intervention study targeting PPIs deprescribing [82]. The implementation of a deprescribing guideline was not associated with a statistically significant decrease in PPIs use [82].

Health information technology (HIT) has the potential to improve medication use in this environment, specifically to reduce the occurrence of medication errors. HIT includes systems such as eMARs, electronic medication management systems, CDSS, electronic health records [62]. Long-term care facilities have lagged behind other sectors in the adoption of HIT because of the lack of funding [62]. The eMAR system was one of the most common types of technology implemented. However, this type of technological support did not extend to supporting clinical decision-making. There was little data on the effect of CDSS in NHs, but there is ongoing research on this topic (83). Its impact in the longterm environment remains to be seen as recent trials on CDSS to optimize prescribing in primary and acute care have shown negative results on clinical outcomes [84, 85]. The relevance of alerts and usability seem to be limiting features, and these finding would be important if this technology were implemented in NHs. Other aspects of technological interventions are also lacking a strong evidence base such as the completeness and accuracy of transfer of medication information at transition moments, and the role of telemedicine.

Evidence is lacking regarding the transferability of interventions across countries and across NHs because barriers and enablers differ. Sometimes, culture and context will overwhelm any attempt to implement an approach that has worked else. However, increasingly, more attention is being paid to how interventions are developed by using recognized frameworks such as the Medical Research Council guidance on the complex interventions [86]. This systematic approach advocates for reference to existing evidence, the use of theory, modeling, pilot/feasibility testing, and implementation. There are now many more examples of interventions being developed using this approach, with a particular emphasis on theories of behavior change [87], and how barriers and enablers can be recognized [88]. A large trial evaluating the effectiveness and cost-effectiveness of a pharmacist-independent prescribing service in NHs compared to usual general practitioner-led care has been conducted in the UK and is due to report soon [89]. This trial also has an embedded process evaluation, to try to understand the mechanisms of action associated with the interventions and to explain findings in terms of fidelity to intervention performance [89]. This rigorous approach to design and evaluation enhances confidence in the conduct and findings of such studies and should be adopted by others seeking to develop and assess interventions in NHs.

\section{Conclusion}

The NH setting and its residents have been a focus for a range of interventions targeting the spectrum of optimizing medicines use. This review has highlighted that a number of interventions are effective, but there is a need for further well-designed and large-scale evaluations of intervention components (e.g., health information technology, patientcentered approaches), specific medication classes (e.g., antithrombotic agents) which have been less commonly studied. Interventions targeting medication use aspects other than prescribing (e.g., monitoring) should also be evaluated. 
Building the evidence base for effective interventions would benefit from the development and uptake of COSs to allow for synthesis of findings. Finally, qualitative studies on barriers and enablers for intervention implementation would enable theory-driven intervention design. This is likely to lead to more robust and rigorous assessments of what is effective in a patient population that has unique health care needs and challenges.

Acknowledgements The authors thank Lorene Zerah for her critical review of the manuscript.

Author contributions All authors have made substantial contributions to the conception of the review, analysis and interpretation of the data, and writing of the manuscript. Perrine Evrard and Anne Spinewine performed the literature search, selection of relevant articles, and initial synthesis of the data. Perrine Evrard wrote the first draft of the manuscript, and this was then critically reviewed and amended by all co-authors.

Funding This research received no specific grant from any funding agency in the public, commercial, or not-for-profit sectors.

\section{Compliance with ethical standards}

Conflict of interest The authors declare that they have no conflicts of interest.

Ethics approval As this is a narrative review, no ethical approval was required.

Informed consent For this type of study, informed consent is not required.

Open Access This article is licensed under a Creative Commons Attribution 4.0 International License, which permits use, sharing, adaptation, distribution and reproduction in any medium or format, as long as you give appropriate credit to the original author(s) and the source, provide a link to the Creative Commons licence, and indicate if changes were made. The images or other third party material in this article are included in the article's Creative Commons licence, unless indicated otherwise in a credit line to the material. If material is not included in the article's Creative Commons licence and your intended use is not permitted by statutory regulation or exceeds the permitted use, you will need to obtain permission directly from the copyright holder. To view a copy of this licence, visit http://creativecommons.org/licenses/by/4.0/.

\section{References}

1. Jokanovic N, Tan EC, Dooley MJ, Kirkpatrick CM, Bell JS (2015) Prevalence and factors associated with polypharmacy in longterm care facilities: a systematic review. J Am Med Dir Assoc 16(6):535.e1-12

2. Spinewine A, Schmader KE, Barber N, Hughes C, Lapane KL, Swine C et al (2007) Appropriate prescribing in elderly people: how well can it be measured and optimised? Lancet (Lond, Engl) 370(9582):173-184
3. Al-Jumaili AA, Doucette WR (2017) Comprehensive literature review of factors influencing medication safety in nursing homes: using a systems model. J Am Med Dir Assoc 18(6):470-488

4. Ferrah N, Lovell JJ, Ibrahim JE (2017) Systematic review of the prevalence of medication errors resulting in hospitalization and death of nursing home residents. J Am Geriatr Soc 65(2):433-442

5. Strauven G, Vanhaecht K, Anrys P, De Lepeleire J, Spinewine A, Foulon V (2020) Development of a process-oriented quality improvement strategy for the medicines pathway in nursing homes using the SEIPS model. Res Soc Adm Pharm RSAP 16(3):360-376

6. Davies LE, Spiers G, Kingston A, Todd A, Adamson J, Hanratty B (2020) Adverse outcomes of polypharmacy in older people: systematic review of reviews. J Am Med Dir Assoc 21(2):181-187

7. Harrison SL, Kouladjian O'Donnell L, Bradley CE, Milte R, Dyer SM, Gnanamanickam ES et al (2018) Associations between the drug burden index, potentially inappropriate medications and quality of life in residential aged care. Drugs Aging 35(1):83-91

8. Veronese N, Stubbs B, Noale M, Solmi M, Pilotto A, Vaona A et al (2017) Polypharmacy is associated with higher frailty risk in older people: an 8-year longitudinal cohort study. J Am Med Dir Assoc 18(7):624-628

9. Morin L, Laroche ML, Texier G, Johnell K (2016) Prevalence of potentially inappropriate medication use in older adults living in nursing homes: a systematic review. J Am Med Dir Assoc 17(9):862.e1-9

10. Anrys PMS, Strauven GC, Foulon V, Degryse JM, Henrard S, Spinewine A (2018) Potentially inappropriate prescribing in belgian nursing homes: prevalence and associated factors. J Am Med Dir Assoc 19(10):884-890

11. Strauven G, Anrys P, Vandael E, Henrard S, De Lepeleire J, Spinewine A et al (2019) Cluster-controlled trial of an intervention to improve prescribing in nursing homes study. J Am Med Dir Assoc 20(11):1404-1411

12. Fleming A, Bradley C, Cullinan S, Byrne S (2015) Antibiotic prescribing in long-term care facilities: a meta-synthesis of qualitative research. Drugs Aging 32(4):295-303

13. Langford AV, Chen TF, Roberts C, Schneider CR (2020) Measuring the impact of system level strategies on psychotropic medicine use in aged care facilities: a scoping review. Res Soc Adm Pharm RSAP 16(6):746-759

14. Alldred DP, Kennedy MC, Hughes C, Chen TF, Miller P (2016) Interventions to optimise prescribing for older people in care homes. Cochrane Database Syst Rev 2:Cd009095

15. Thiruchelvam K, Hasan SS, Wong PS, Kairuz T (2017) Residential aged care medication review to improve the quality of medication use: a systematic review. J Am Med Dir Assoc 18(1):87.e1e14

16. Kua CH, Mak VSL, Huey Lee SW (2019) Health outcomes of deprescribing interventions among older residents in nursing homes: a systematic review and meta-analysis. J Am Med Dir Assoc 20(3):362-72.e11

17. Fog AF, Kvalvaag G, Engedal K, Straand J (2017) Drug-related problems and changes in drug utilization after medication reviews in nursing homes in Oslo, Norway. Scand J Prim Health Care 35(4):329-335

18. Wouters H, Scheper J, Koning H, Brouwer C, Twisk JW, van der Meer $\mathrm{H}$ et al (2017) Discontinuing inappropriate medication use in nursing home residents: a cluster randomized controlled trial. Ann Intern Med 167(9):609-617

19. Cool C, Cestac P, McCambridge C, Rouch L, de Souto BP, Rolland $Y$ et al (2018) Reducing potentially inappropriate drug prescribing in nursing home residents: effectiveness of a geriatric intervention. Br J Clin Pharmacol 84(7):1598-1610

20. Husebø BS, Ballard C, Aarsland D, Selbaek G, Slettebo DD, Gulla $C$ et al (2019) The effect of a multicomponent intervention on 
quality of life in residents of nursing homes: a randomized controlled trial (COSMOS). J Am Med Dir Assoc 20(3):330-339

21. Wouters H, Foster JM, Ensink A, O'Donnell LK, Zuidema SU, Boersma $\mathrm{F}$ et al (2019) Barriers and facilitators of conducting medication reviews in nursing home residents: a qualitative study. Front Pharmacol 10:1026

22. Gulla C, Flo E, Kjome RLS, Husebo BS (2019) Implementing a novel strategy for interprofessional medication review using collegial mentoring and systematic clinical evaluation in nursing homes (COSMOS). BMC Geriatr 19(1):130

23. Anrys P, Strauven G, Roussel S, Vande Ginste M, De Lepeleire J, Foulon V et al (2019) Process evaluation of a complex intervention to optimize quality of prescribing in nursing homes (COMEON study). Implement Sci IS 14(1):104

24. Turner JP, Edwards S, Stanners M, Shakib S, Bell JS (2016) What factors are important for deprescribing in Australian long-term care facilities? Perspectives of residents and health professionals. BMJ Open 6(3):e009781

25. Foley RA, Hurard LL, Cateau D, Koutaissoff D, Bugnon O, Niquille A (2020) Physicians', nurses' and pharmacists' perceptions of determinants to deprescribing in nursing homes considering three levels of action: a qualitative study. Pharm (Basel, Switz) $8(1): 17$

26. van der Spek K, Koopmans R, Smalbrugge M, Nelissen-Vrancken M, Wetzels RB, Smeets CHW et al (2018) The effect of biannual medication reviews on the appropriateness of psychotropic drug use for neuropsychiatric symptoms in patients with dementia: a randomised controlled trial. Age Ageing 47(3):430-437

27. Richter C, Berg A, Langner H, Meyer G, Köpke S, Balzer K et al (2019) Effect of person-centred care on antipsychotic drug use in nursing homes (EPCentCare): a cluster-randomised controlled trial. Age Ageing 48(3):419-425

28. Weeks WB, Mishra MK, Curto D, Petersen CL, Cano P, Hswen Y et al (2019) Comparing three methods for reducing psychotropic use in older demented spanish care home residents. J Am Geriatr Soc 67(7):1444-1453

29. Wauters M, Elseviers M, Peeters L, De Meester D, Christiaens T, Petrovic M (2019) Reducing psychotropic drug use in nursing homes in belgium: an implementation study for the roll-out of a practice improvement initiative. Drugs Aging 36(8):769-780

30. Plüss-Suard C, Niquille A, Héquet D, Krähenbühl S, Pichon R, Zanetti G et al (2020) Decrease in antibacterial use and facilitylevel variability after the introduction of guidelines and implementation of physician-pharmacist-nurse quality circles in swiss long-term care facilities. J Am Med Dir Assoc 21(1):78-83

31. Janus SI, van Manen JG, Izerman MJ, Zuidema SU (2016) Psychotropic drug prescriptions in Western European nursing homes. Int Psychogeriatr 28(11):1775-1790

32. Ivers NM, Taljaard M, Giannakeas V, Reis C, Williams E, Bronskill S (2019) Public reporting of antipsychotic prescribing in nursing homes: population-based interrupted time series analyses. BMJ Qual Saf 28(2):121-131

33. de Souto BP, Lapeyre-Mestre M, Cestac P, Vellas B, Rolland Y (2016) Effects of a geriatric intervention aiming to improve quality care in nursing homes on benzodiazepine use and discontinuation. Br J Clin Pharmacol 81(4):759-767

34. Storms H, Marquet K, Aertgeerts B, Claes N (2017) Prevalence of inappropriate medication use in residential long-term care facilities for the elderly: a systematic review. Eur J Gen Pract 23(1):69-77

35. Abdeljalil A-B, Arbus C, Montastruc F, de Souto BP, André L, Vellas B et al (2019) Antidepressants in nursing homes for dependent older patients: the cross-sectional associations of institutional factors with prescription conformance. Eur Geriatr Med $10(3): 421-430$
36. Evrard P, Henrard S, Foulon V, Spinewine A (2020) Benzodiazepine use and deprescribing in belgian nursing homes: results from the COME-ON study. J Am Geriatr Soc 68:2768-2777

37. Walsh KA, Dennehy R, Sinnott C, Browne J, Byrne S, McSharry J et al (2017) Influences on decision-making regarding antipsychotic prescribing in nursing home residents with dementia: a systematic review and synthesis of qualitative evidence. J Am Med Dir Assoc 18(10):8971-9012

38. Harrison SL, Cations M, Jessop T, Hilmer SN, Sawan M, Brodaty $\mathrm{H}$ (2019) Approaches to deprescribing psychotropic medications for changed behaviours in long-term care residents living with dementia. Drugs Aging 36(2):125-136

39. Ng BJ, Le Couteur DG, Hilmer SN (2018) Deprescribing benzodiazepines in older patients: impact of interventions targeting physicians, pharmacists, and patients. Drugs Aging 35(6):493-521

40. Nakham A, Myint PK, Bond CM, Newlands R, Loke YK, Cruickshank M (2020) Interventions to reduce anticholinergic burden in adults aged 65 and older: a systematic review. J Am Med Dir Assoc 21(2):172-80.e5

41. Chatterjee S, Bali V, Carnahan RM, Chen H, Johnson ML, Aparasu RR (2017) Risk of mortality associated with anticholinergic use in elderly nursing home residents with depression. Drugs Aging 34(9):691-700

42. Aalto UL, Finne-Soveri H, Kautiainen H, Roitto H-M, Öhman H, Pitkälä KH (2019) Use of anticholinergic drugs according to various criteria and their association with psychological well-being and mortality in long-term care facilities. J Am Med Dir Assoc 20(9):1156-1162

43. Aalto UL, Roitto H-M, Finne-Soveri H, Kautiainen H, Pitkälä KH (2020) Temporal trends in the use of anticholinergic drugs among older people living in long-term care facilities in helsinki. Drugs Aging 37(1):27-34

44. Kersten H, Molden E, Tolo IK, Skovlund E, Engedal K, Wyller TB (2012) Cognitive effects of reducing anticholinergic drug burden in a frail elderly population: a randomized controlled trial. $\mathrm{J}$ Gerontol Ser A 68(3):271-278

45. Ailabouni N, Mangin D, Nishtala PS (2019) DEFEAT-polypharmacy: deprescribing anticholinergic and sedative medicines feasibility trial in residential aged care facilities. Int J Clin Pharm 41(1): $167-178$

46. Ricchizzi E, Latour K, Kärki T, Buttazzi R, Jans B, Moro ML et al (2018) Antimicrobial use in European long-term care facilities: results from the third point prevalence survey of healthcare-associated infections and antimicrobial use, 2016 to 2017. Eurosurveillance 23(46): 1800394

47. Lavan AH, Gallagher P, Parsons C, O'Mahony D (2017) STOPPFrail (Screening tool of older persons prescriptions in frail adults with limited life expectancy): consensus validation. Age Ageing 46(4):600-607

48. Feldstein D, Sloane PD, Feltner C (2018) Antibiotic stewardship programs in nursing homes: a systematic review. J Am Med Dir Assoc 19(2):110-116

49. Wu JHC, Langford BJ, Daneman N, Friedrich JO, Garber G (2019) Antimicrobial stewardship programs in long-term care settings: a meta-analysis and systematic review. J Am Geriatr Soc 67(2):392-399

50. Nguyen HQ, Tunney MM, Hughes CM (2019) Interventions to improve antimicrobial stewardship for older people in care homes: a systematic review. Drugs Aging 36(4):355-369

51. Van Buul LW, Monnier AA, Sundvall P-D, Ulleryd P, GodyckiCwirko M, Kowalczyk A et al (2020) Antibiotic stewardship in European nursing homes: experiences from the Netherlands, Norway, Poland, and Sweden. J Am Med Dir Assoc 21(1):34-40.e1

52. Arnold SH, Olesen JA, Jensen JN, Bjerrum L, Holm A, Kousgaard MB (2020) Development of a tailored, complex intervention for clinical reflection and communication about suspected urinary 
tract infections in nursing home residents. Antibiot (Basel, Switz) 9(6):30

53. Chhabra PT, Rattinger GB, Dutcher SK, Hare ME, Parsons KL, Zuckerman IH (2012) Medication reconciliation during the transition to and from long-term care settings: a systematic review. Res Soc Adm Pharm RSAP 8(1):60-75

54. LaMantia MA, Scheunemann LP, Viera AJ, Busby-Whitehead J, Hanson LC (2010) Interventions to improve transitional care between nursing homes and hospitals: a systematic review. J Am Geriatr Soc 58(4):777-782

55. Terrell KM, Miller DK (2011) Strategies to improve care transitions between nursing homes and emergency departments. J Am Med Dir Assoc 12(8):602-605

56. Scholl I, Kriston L, Dirmaier J, Buchholz A, Harter M (2012) Development and psychometric properties of the Shared Decision Making Questionnaire-physician version (SDM-Q-Doc). Patient Educ Couns 88(2):284-290

57. Dubé P-A, Portelance J, Corbeil O, Tessier M, St-Onge M (2018) Drug administration to the wrong nursing home residents reported to the québec poison center: a retrospective study. J Am Med Dir Assoc 19(10):891-895

58. Odberg KR, Hansen BS, Aase K, Wangensteen S (2018) Medication administration and interruptions in nursing homes: a qualitative observational study. J Clin Nurs 27(5-6):1113-1124

59. Forough AS, Wong SYM, Lau ETL, Santos JMS, Kyle GJ, Steadman KJ et al (2018) Nurse experiences of medication administration to people with swallowing difficulties living in aged care facilities: a systematic review of qualitative evidence. JBI Database Syst Rev Implement Rep 16(1):71-86

60. Fuller AEC, Guirguis LM, Sadowski CA, Makowsky MJ (2018) Electronic medication administration records in long-term care facilities: a scoping review. J Am Geriatr Soc 66(7):1428-1436

61. Qian S, Yu P, Hailey D, Wang N, Bhattacherjee A (2018) Medication administration process in a residential aged care home: an observational study. J Nurs Manag 26(8):1033-1043

62. Kruse CS, Mileski M, Syal R, MacNeil L, Chabarria E, Basch C (2020) Evaluating the relationship between health information technology and safer-prescribing in the long-term care setting: a systematic review. Technol Health Care 28:1-14

63. Gilmartin-Thomas JF, Smith F, Wolfe R, Jani Y (2017) A comparison of medication administration errors from original medication packaging and multi-compartment compliance aids in care homes: a prospective observational study. Int J Nurs Stud 72:15-23

64. Millar AN, Daffu-O'Reilly A, Hughes CM, Alldred DP, Barton G, Bond CM et al (2017) Development of a core outcome set for effectiveness trials aimed at optimising prescribing in older adults in care homes. Trials 18(1):175

65. Beuscart JB, Knol W, Cullinan S, Schneider C, Dalleur O, Boland B et al (2018) International core outcome set for clinical trials of medication review in multi-morbid older patients with polypharmacy. BMC Med 16(1):21

66. Khodyakov D, Ochoa A, Olivieri-Mui BL, Bouwmeester C, Zarowitz BJ, Patel M et al (2017) Screening tool of older person's prescriptions/screening tools to alert doctors to right treatment medication criteria modified for US nursing home setting. J Am Geriatr Soc 65(3):586-591

67. Hughes CM, Roughead E, Kerse N (2008) Improving use of medicines for older people in long-term care: contrasting the policy approach of four countries. Healthc Policy Politiques de Sante 3(3):154-167

68. Brownlee K, Devins G, Flanigan M, Fleming J, Morehouse R, Moscovitch A et al (2003) Are there gender differences in the prescribing of hypnotic medications for insomnia? England 18:69-73

69. Van Malderen L, De Vriendt P, Mets T, Verté D, Gorus E (2017) Experiences and effects of structurally involving residents in the nursing home by means of participatory action research: a mixed method study. J Am Med Dir Assoc 18(6):495-502

70. Kales HC, Gitlin LN, Lyketsos CG (2019) When less is more, but still not enough: why focusing on limiting antipsychotics in people with dementia is the wrong policy imperative. J Am Med Dir Assoc 20(9):1074-1079

71. McClean P, Hughes C, Tunney M, Goossens H, Jans B (2011) Antimicrobial prescribing in European nursing homes. J Antimicrob Chemother 66(7):1609-1616

72. Nguyen HQ, Bradley DT, Tunney MM, Hughes CM (2020) Antimicrobial stewardship in care homes: outcomes of importance to stakeholders. J Hosp Infect 104(4):582-591

73. La Frenais FL, Bedder R, Vickerstaff V, Stone P, Sampson EL (2018) Temporal trends in analgesic use in long-term care facilities: a systematic review of international prescribing. J Am Geriatr Soc 66(2):376-382

74. Hunnicutt JN, Chrysanthopoulou SA, Ulbricht CM, Hume AL, Tjia J, Lapane KL (2018) Prevalence of long-term opioid use in long-stay nursing home residents. J Am Geriatr Soc 66(1):48-55

75. Könner F, Budnick A, Kuhnert R, Wulff I, Kalinowski S, Martus $P$ et al (2015) Interventions to address deficits of pharmacological pain management in nursing home residents - a cluster-randomized trial. Eur J Pain (Lond, Engl) 19(9):1331-1341

76. Malekakan A, van Hout H, Onder G, Finne-Soveri $\mathrm{H}$, van der Roest H, van Marum R (2017) Prevalence of preventive cardiovascular medication use in nursing home residents. Room for deprescribing the SHELTER Study. J Am Med Dir Assoc 18(12):1037-1042

77. Goyal P, Anderson TS, Bernacki GM, Marcum ZA, Orkaby AR, Kim D et al (2020) Physician perspectives on deprescribing cardiovascular medications for older adults. J Am Geriatr Soc 68(1):78-86

78. Jokanovic N, Kautiainen H, Bell JS, Tan ECK, Pitkala KH (2019) Change in prescribing for secondary prevention of stroke and coronary heart disease in finnish nursing homes and assisted living facilities. Drugs Aging 36(6):571-579

79. Teramura-Grönblad M, Hosia-Randell H, Muurinen S, Pitkala K (2010) Use of proton-pump inhibitors and their associated risks among frail elderly nursing home residents. Scand J Prim Health Care 28(3):154-159

80. Rane PP, Guha S, Chatterjee S, Aparasu RR (2017) Prevalence and predictors of non-evidence based proton pump inhibitor use among elderly nursing home residents in the US. Res Soc Adm Pharm RSAP 13(2):358-363

81. Linsky A, Hermos JA, Lawler EV, Rudolph JL (2011) Proton pump inhibitor discontinuation in long-term care. J Am Geriatr Soc 59(9):1658-1664

82. Thompson W, Hogel M, Li Y, Thavorn K, O’Donnell D, McCarthy L et al (2016) Effect of a proton pump inhibitor deprescribing guideline on drug usage and costs in long-term care. J Am Med Dir Assoc 17(7):673.e1-4

83. Mestres Gonzalvo C, de Wit HA, van Oijen BP, Hurkens KP, Janknegt R, Schols JM et al (2017) Supporting clinical rules engine in the adjustment of medication (SCREAM): protocol of a multicentre, prospective, randomised study. BMC Geriatr 17(1):35

84. O’Mahony D, Gudmundsson A, Soiza RL, Petrovic M, Jose CruzJentoft A, Cherubini A et al (2020) Prevention of adverse drug reactions in hospitalized older patients with multi-morbidity and polypharmacy: the SENATOR* randomized controlled clinical trial. Age Ageing 49(4):605-614

85. Rieckert A, Reeves D, Altiner A, Drewelow E, Esmail A, Flamm $M$ et al (2020) Use of an electronic decision support tool to reduce polypharmacy in elderly people with chronic diseases: cluster randomised controlled trial. BMJ (Clin Res ed) 369:m1822

86. Craig P, Dieppe P, Macintyre S, Michie S, Nazareth I, Petticrew M (2008) Developing and evaluating complex interventions: the new Medical Research Council guidance. BMJ (Clin Res ed) 337:a1655 
87. Hughes CM, Cadogan CA, Ryan CA (2016) Development of a pharmacy practice intervention: lessons from the literature. Int J Clin Pharm 38(3):601-606

88. Cadogan CA, Ryan C, Hughes C (2016) Making the case for change: what researchers need to consider when designing behavior change interventions aimed at improving medication dispensing. Res Soc Adm Pharm RSAP 12(1):149-153

89. Bond CM, Holland R, Alldred DP, Arthur A, Barton G, Birt L et al (2020) Protocol for the process evaluation of a cluster randomised controlled trial to determine the effectiveness and cost-effectiveness of independent pharmacist prescribing in care home: the CHIPPS study. Trials 21(1):439

Publisher's Note Springer Nature remains neutral with regard to jurisdictional claims in published maps and institutional affiliations. 